\title{
A ÉTICA CRISTÃ A PARTIR DE UMA LEITURA DE HEGEL E NIETZSCHE
}

\author{
Adilson Felicio Feiler ${ }^{1}$ \\ Universidade do Vale do Rio dos Sinos (UNISINOS) \\ https://orcid.org/0000-0001-7352-927X
}

\section{RESUMO:}

A aproximação que apresentamos entre Hegel e Nietzsche não é uma reconciliação entre ambos, mas uma investigação da crítica que ambos fazem com relação a moral cristã, ou seja, do destino que o Cristianismo assumiu a partir da "tradição cristã", resultando no afastamento de seu espírito. Esse afastamento se dá a partir da cristalização de suas doutrinas em dogmas, implicando num estranhamento de Deus. Nietzsche lê este estranhamento através da moral, portanto uma falsificação do verdadeiro espírito cristão pela cristandade.

PALAVRAS-CHAVE: Cristianismo; Ética; Moral; Amor; Destino.

\section{THE CHISTIAN ETHICS FROM A READING OF HEGEL AND NIETZSCHE}

\begin{abstract}
:
The approach that we present between Hegel and Nietzsche is not an approach between both, but an investigation of the critic that both do with respect to christian moral, namely, of the fate that the Christianism assumed from the "christian tradition", that resulted in the remoteness of its spirit. This remoteness happens from the crystalization of its doctrines and dogmas, that implies in an estrangement of God. Nietzsche reads this estrangement through the moral, hence a falsification of the truly christian spirit by the christianity.
\end{abstract}

KEYWORDS: Christianism; Ethics; Moral; Love; Fate.

\footnotetext{
${ }^{1}$ Doutor em Filosofia pela Pontifícia Universidade Católica do Rio Grande do Sul (PUCRS), Rio Grande do Sul - Brasil. Professor da Universidade do Vale do Rio dos Sinos (UNISINOS), Rio Grande do Sul-Brasil. E-mail: afeiler@unisinos.br
}

FEILER, Adilson Felicio. A ética cristã a partir de uma leitura de Hegel e Nietzsche. Griot : Revista de Filosofia, Amargosa, Bahia, v.16, n.2, p.25-35, dezembro/2017. 


\section{Introdução}

Temos o propósito de mostrar certa coincidência fundamental no modo de julgar o ethos cristão, entre as posições filosóficas que, além de muito distantes uma da outra desde o ponto de vista cronológico, parecem representar dois modos profundamente antitéticos de compreender não só a verdade, senão a filosofía mesma e a sua tarefa: as posições de Hegel e de Nietzsche. $O$ meio que nos valemos para afirmar a existência, em ambas, de uma certa coincidência e não só oposição e divergência, consistirá em realizar um breve exame dos escritos em que os respectivos autores deliberam sobre um mesmo assunto: o Cristianismo, a doutrina cristã e, em relação com ela, a vida e o significado histórico de seu fundador, Jesus de Nazaré.

Apresentamos, na Introdução, o propósito da investigação e seus delineamentos metodológicos e, na Conclusão, apreciamos a unidade sistemática das distintas partes sob a forma de uma recapitulação geral dos resultados obtidos. $\mathrm{O}$ corpo principal da investigação se articula em três grandes partes destinadas a mostrar de que maneira, à luz das reflexões de Hegel e de Nietzsche, os pontos vitais culminantes Lebenshöhepunkte do ethos cristão se expressam de maneira sucessiva e diversificada, primeiro como potencialidade Leistungsfähigkeit, em seguida como reciprocidade Vielfältigkeit e, finalmente, como reciprocidade Gegenseitigkeit. Por sua parte, cada um destes três conceitos são examinados e expostos em relação com uma forma determinada de saber: o primeiro, potencialidade, com a fenomenologia; o segundo, diversidade, com a lógica; e o terceiro, reciprocidade, com a política.

Esta articulação sistêmica, que revela o matéria de nossa investigação, segundo a natureza de uma ordem que a filosofia tem cultivado durante séculos como próprio da inteligência. Essa ordem se comunica através das três partes que se articulam, ou seja, de maneira triádica. O primeiro capítulo está determinado pela idéia da imediatez; o segundo pela ideía de oposição que torna possível o trabalho de mediação e, com este, a superação dialética da imediatez inicial; enquanto que, no terceiro e último capítulo, está concebido um resultado em sentido especulativo, como a verdade e a oposição, verdade que tanto o escrito de Hegel como o de Nietzsche apresentam sob a forma de uma reconciliação, esteja vinculada tanto com a noção de Destino como com a noção de Amor.

Seguimos, no desenvolvimento de nossa investigação, os passos metodológicos da dialética, principiando com uma imediatez, passando por uma mediação e confluindo em uma reconciliação destes dois momentos anteriores: uma reconciliação aberta à plenitude e a novas reconciliações. Todos estes momentos constituem um tecido de três capítulos: a fenomenologia, para principiar pela dimensão descritiva do fenômeno do ethos cristão; a lógica, para fazer uma sistematização e a crítica do ethos cristão; e a política para culminar na aplicação do ethos cristão em sua dimensão social.

Todo o intento se estriba no esforço de configurar uma unidade de caráter lógico. Este aspecto formal, portanto, longe de ser algo meramente secundário, reflete um de nossos momentos mais originais. A subdivisão, por fim, de cada um dos três capítulos, dentro de cada seção se reflete na macroestrutura triádica do conjunto.

FEILER, Adilson Felicio. A ética cristã a partir de uma leitura de Hegel e Nietzsche. Griot : Revista de Filosofia, 


\section{$\mathbf{O}$ fenômeno potencial imediato}

Partimos, na fenomenologia, de um ponto comum: da unidade hegeliana imediata, aquela fonte e princípio a nada determinado e da duplicidade nietzschiana, marcada pelas disposições artísticas, apolínea e dionisíaca, enquanto meras manifestações artísticas são ambas realidades imediatas. Logo, tanto a unidade como a duplicidade são realidades imediatas abertas que anseiam pela plenitude, portanto Leistungsfähingkeit (potencialidade), uma força que se expressa como fenomenologia romântica. Portanto, na vida que atinge a maximização da potência, temos uma abertura que nos permite desconstruir a moral e abrir a possibilidade de um projeto ético na própria pessoa de Jesus e sua prática, que valoriza todas as inclinações humanas, como em alimentar as multidões pela multiplicação dos pães ${ }^{2}$. Daqui se depreende que o específico e o próprio do Cristianismo “(...) está em considerar a esse Jesus como decisiva e última instância, como critério final para o ser humano naquelas suas diferentes dimensões. ${ }^{3} "$ Em sendo Jesus o critério último do Cristianismo, sua mensagem se traduz na $\operatorname{singularidade}^{4}$ que se depreende de sua vida.

Os escritos sobre os quais nos baseamos para o trabalho de nossa investigação não respondem por si mesmos a uma ordem lógica. O Espírito do Cristianismo e seu Destino, foi escrito em Frankfurt entre 1798 e 1800, quando a ideia de sistema ainda estava em gérmen, no espírito de seu autor, e o Anticristo, obra de um pensador que rechaçou com todo o vigor a validez da ideia de sistema e da ordem lógica. Em meio a aproximações e distanciamentos, ambos escritos, revelam cada um o seu modo de valorar o ethos cristão. No entanto, a nossa ordem expositiva procura traçar algo novo, livre de preconceitos e jargões que tem se cristalizado em torno destes autores.

$O$ Espírito do Cristianimo pertence a todo um conjunto de textos que, tendo sido redigidos durante a primeira juventude, Hegel prefiriu não publicá-los por julgá-los imaturos, em comparação com o desenvolvimento posterior de toda a sua obra especulativa. No entanto, a nossa opção por estes textos repousam sobre o fato de que é unicamente mediante estes que se tona possível alguma aproximação com Nietzsche, focando principalmente a lógica pobre de Hegel, pois estamos ciente de que, para uma compreensão mais precisa do ethos cristão em Hegel, são oferecidas as suas Lições sobre a Filosofia da Religião e Sobre a Filosofia da História.

Em relação ao Espírito do Cristianismo cabe fazer uma breve consideração de caráter historiográfico que pode resultar oportuna. $O$ horizonte sobre o qual se depreende esta obra tem deixado de ser o dos escritos de Berna, entre os que figura a Vida de Jesus; agora, em lugar da pergunta pelo surgimento da positividade dentro de uma religião moral pura, o determinante para Hegel é a oposição dialética entre divisão e unificação. Produz-se assim, como soube observar Dilthey, um giro intelectual desde o kantismo até o panteísmo mítico. Segundo Dieter Henrich, este panteísmo mítico, que acusa um transfundo neoplatônico, abrevia as fontes que tem sido possível determinar de maneira precisa: os escritos de Lord Shaftesbury, a Lettre sur désirs de Hemsterhuis, Liebe und Selbstheit de Herder, a Teosofia de Julio, de

2 Cf. Mt 14,15-20

${ }^{3}$ Cf. KÜNG, 1976, p. 102

4 Ídem, p. 94

FEILER, Adilson Felicio. A ética cristã a partir de uma leitura de Hegel e Nietzsche. Griot : Revista de Filosofia, 
Schiller. Estes textos contribuem para configurar, de maneira decisiva o clima ideológico de onde se gestam e amadurecem as ideias fundamentais dos porta-vozes do chamado idealismo alemão.

Entre as dívidas imediatas de Hegel para com o pensamento de seu tempo não é possível deixar de assinalar que o emprego característico da palavra "amor" e, sobretudo, da palavra "ser" como sinônimo de "vida pura", assim o usa também Hölderlin em Urteil und Seyn. Ora, tudo isso resulta praticamente incompreensível se não se tem em conta a Jacobi: por um lado, a fórmula do panteísmo cunhada por ele, segundo o qual "Deus é o ser em toda a existência", e, por outro, seu escrito intitulado Pensamentos fundamentais acerca do amor da própria vida na relação dos viventes entre si e da manifestação de Deus que há nele. Deus é, portanto, uma presença imediata que se faz sentir como fatum entre os seres humanos.

\section{A lógica diversa mediata}

Esse ser, em sua imediatidade, tende num momento seguinte a se deparar com o seu oposto, portanto uma Vielfältigkeit (diversidade) e, desta oposição que anseia por estabelecer redes, surge uma lógica. A lógica, em Hegel, se depreende a partir do desbobramento daquela unidade imediata e da tensão da duplicidade em sua imediatidade como Leistungsfähigkeit (potencialidade) num outro dela mesma e em um oposto na Vielfältigkeit (diversidade). Nesta proposta ética de apresentar Deus como pessoa, sob a terminologia Reino de Deus, Jesus, em nome desta força Leistungsfähigkeit (potencialidade), representada pelo Reino de Deus, nega tudo o que se opõe a ele, e, dessa negação, se evidencia a Vielfältigkeit (diversidade) de diferenças solapadas pela moral: certa concepção da lei que se impõe como estranha ${ }^{5}$. Daqui se depreende a antítese entre Jesus e "Deus": Jesus como pessoa em sua mensagem e prática singular “(...) ergue-se face ao Deus tenebroso e cruel e, muitas vezes, incompreensível. ${ }^{6 "}$ Tanto Hegel como Nietzsche, no esforço deles partir de uma imediatidade, a fim de romper com a cristalização dogmática, se lançam contra a ordem estabelecida. Nietzsche vê a necessidade de culminar em: “(..) um ser de outro modo" (NIETZSCHE, AC, KSA, §, 39, 1999, p. 211), portanto aberto à Vielfältigkeit (diversidade). Ou seja, ambas as imediatidades, a unidade interna e a duplicidade externa, convergem na Vielfältigkeit (diversidade), com acento no valor da diferença para a constituição de uma totalidade que integra a vida em sua plenitude. A relação entre estas partes reflete abertura e amor ao destino, salvaguarda do movimento da plenitude da vida a atingir sempre pontos mais culminantes, Lebenshöhepunkte, que é uma ética em movimento, traduzida numa prática. A prática de Jesus aponta para um ethos sempre em movimento.

Em virtude do mencionado giro intelectual se explica por que Hegel, ao abordar em sua interpretação do Cristianismo como religião, em vez de manter fixa sua atenção sobre a "moralidade", começa a falar primeiro de "amor", logo de "vida", até ao final de seu período de Frankfurt, e posteriormente, em Jena, de "espírito", portanto, amor, vida e espírito inspiram uma ética em movimento e flexibilidade.

\footnotetext{
${ }^{5}$ Cf. Mt 5,17

${ }^{6}$ Cf. KÜNG, 1976, p. 120
}

FEILER, Adilson Felicio. A ética cristã a partir de uma leitura de Hegel e Nietzsche. Griot : Revista de Filosofia, 
No caso de Nietzsche, $\mathrm{O}$ Anticristo surge em uma fase tardia da vida do autor, quando ele já havia deliberado sobre o Cristianismo e sobre o ethos cristão, primeiro em Humano, demasiado humano e logo em Aurora, na Gaya Ciência, no Zaratustra, e na Genealogia da moral. Contudo, é no Anticristo que aparece, de maneira mais clara e explícita, a crítica de Nietzsche ao Cristianismo, ante a um modo pelo qual ele (o Cristianismo) tem sido vivido, a saber, como moral, e não como uma prática. Eis, portanto, a novidade que o Anticristo aporta, não sendo simplesmente uma reiteração de elementos já mencionados em obras anteriores. É sabido que o pensamento de Nietzsche pode ser compreendido em termos gerais, como o faz Heidegger, ao reconhecer nele o final histórico da metafísica; final que não consiste senão em investigação do começo platônico daquela; trata-se de uma interpretação fecunda e consequente, sobretudo porque permite situar historicamente a mediação nietzschiana em relação à pergunta pela destinação da coisa do pensar. $O$ certo é que também existe outra interpretação, difundida sobretudo no mundo anglosaxão, e um de cujos expoentes principais é Walter Kaufmann, que acentua o aspecto psicológico da reflexão nietzschiana. Nossa investigação repousa sobre esta segunda vertente, que nos permite reconhecer aquela síntese como unidades momentâneas que, ao alcançarem seu auge, se diluem; aquelas bases metafísicas sobre as quais a psicologia clássica outrora se assentava ao identificar o psíquico ao consciente passando a se constituir enquanto ciência da subjetividade na diferenciação entre o consciente e o inconsciente. E, como lembra Oswaldo Giacóia Júnior, é justamente na “[...] dissolução da unidade substancial da alma" que a proposta Nietzschiana se levanta como "[...] um dos principais efeitos de sua crítica da moral, da religião e da metafísica." ${ }^{8} \mathrm{Com}$ isso, a psique, desembaraçada do fetichismo ocasionado pela moral, se apresenta como uma síntese em unidades momentâneas, como pontos culminantes de vida que, ao se diluírem, abrem espaço a novas potencialidades a perfazerem continuamente o processo que serve de base teórica à doutrina científica da subjetividade. Acreditamos que a perspectiva psicológica pode resultar frutífera no que diz respeito à questão que, tanto Hegel como Nietzsche, colocam: que tipo de ser humano é capaz de viver neste mundo moderno, não submisso aos ditames do turbilhão niilista? Pois o niilismo é teoricamente possível, porém psicologicamente impossível, ou seja, as instituições criadas pela sociedade são importantes na medida em que impedem com que se pense no niilismo e, assim, não se venha a nada criar, no dizer de Nietzsche, a nada querer.

No Anticristo de Nietzsche aparecem muitos temas tratados por Hegel no Espírito do Cristianismo; Nietzsche inclusive teria aprovado esta obra juvenil de Hegel, mas é certo que cabe dar por seguro que não chegou a lê-la. Ainda mais: cabe sustentar que alguns pontos são possíveis de aproximar ao sistema dialético vitalista incipiente do jovem Hegel ao organicismo de Nietzsche. Dentre os temas que permitem ver, em Hegel e Nietzsche, uma certa comunhão de interesse, há dois aos quais destacamos: a) Apesar de suas distâncias, ambos comungam de um projeto comum: a crítica à metafísica. No caso de Nietzsche, a crítica a metafísica responde ao desígnio característico da modernidade em sentido singular [moderne]: trata-se de rechaçar como inválida ou errada a tradição do pensamento ocidental em seu

${ }^{7}$ Cf. GIACÓIA JÚNIOR, 2001, p. 25

8 Ibidem, p. 26

FEILER, Adilson Felicio. A ética cristã a partir de uma leitura de Hegel e Nietzsche. Griot : Revista de Filosofia, Amargosa, Bahia, v.16, n.2, p.25-35, dezembro/2017. 
conjunto, tachada de "platonismo", como ele diz: (...) "Más e anti-humanas chamo todas essas doutrinas do uno e perfeito e imóvel" (NIETZSCHE, Assim falou Zaratustra II, 2: "Nas Ilhas bem-aventuradas, p. 115) -, uma rejeição em virtude da qual as reflexões do próprio Nietzsche só podem organizar-se de forma "livre" ou "rapsódica" ou, em termos gerais, não-sistemática. No caso de Hegel, a crítica se dirige de maneira precisa a uma forma de metafísica, isto é, a da reflexão exterior. Trata-se da mesma metafísica que, enquanto constitue uma primeira posição do pensamento frente a objetividade, já Kant reconheceu como uma simples forma de dogmatismo. Trata-se de superar esse dogmatismo e de que a metafísica, também graças ao enorme esforço especulativo de Fichte, se justificasse no sentido da ciência, de um saber incondicionado. Esta questão alcança seu acabamento mais pleno, como bem se sabe, na figura sistemática da Enciclopédia das Ciências Filosóficas. A reflexão nietzscheana, por sua parte, possui o mérito, de ter-se distanciado, pela negação, do dualismo metafísico categorial em uma totalidade perspectivística que se desconstrói de maneira orgânica. b) $O$ outro ponto em que Hegel e Nietzsche parecem coincidir é a crítica ao formalismo da lei moral kantiana e cristã, frente à qual (ambos os autores) apresentam o ação de Jesus, tal como ele se apresenta no Evangelho de João, o Evangelho que, ao acentuar a prática de unidade em plenitude pelo movimento espiritual do Logos, reflete a soberania daquele que é responsável por ela. Esta soberania que se expressa, de modo particular, em sua ética do amor fati, uma ética do "Sim" para além de uma vida não degenerada pelo Cristianismo dogmático e pela filantropia moderna da compaixão. Poderíamos perguntar-nos: por que Hegel omite os escritos paulinos? Hegel não considera a teologia paulina, por centrar sua investigação sobre a prática de Jesus e não no seu legado histórico, o que para Nietzsche, inclusive, é considerado uma degeneração e até falsificação de Paulo daquilo que foi a prática de Jesus. Esta falsificação repousaria sobre a confusão entre prática e moral. A moral é, pois, um alvo da crítica de ambos os autores. Embora Hegel critique a moral kantiana por seu formalismo ou rigidez, isto não o converte em negador de toda a moral, mas de uma certa compreensão que se teve da mesma, a saber, formal e positiva. Em Nietzsche a moral se apresenta como obediência a normas hostis à vida; uma compreensão da moral como daquilo que "não deve ser" associado com uma compreensão não menos negativa da natureza da lei enquanto tal. Assim, a moral é prejudicial quando vem associada a uma compreensão de normas vazias de conteúdo de uma forma rígida e artificial. Pois, pelo contrário, a moral aristotélica, que é base para a sua reflexão em torno da virtude, bem como a moral como base sobre o Tratado sobre os deveres de Cícero, é tida em alta estima.

A moral cristã deve ser combatida em suas orígens, tal como se apresenta entre os mesmos seguidores de Jesus, entre seus apóstolos, porque sufoca a prática de vida inaugurada por Jesus de Nazaré. É claro, no entanto, que toda a prática, na medida em que não se sujeita a uma norma e que responda a um propósito sempre acidental ou contingente, resulta irracional. Se Jesus age com segurança e liberdade, é porque compreende a razão de seu agir e essa razão, por sua própria inteligibilidade, pode ser formulada como um princípio capaz de regular o agir.

É comum, tanto em Hegel como em Nietzsche, considerar os dogmas da moral cristã como estranhos ao ser humano, enquanto que o homem romântico 
estaria animado por um impulso que o conduziria à abertura, no sentido de uma certa plenitude, ou melhor, até a aceitação do destino, entendido como porvir. Por isso o homem romântico busca superar, por todos os meios, os obstáculos representados pela moral, pelas leis e outros interditos ditados por instâncias externas e estranhas ao ser humano. Mais uma vez. somos levados a considerar que a moral teve e tem um papel importante no universo ético. O que pesa na leitura de Hegel e Nietzsche é, certamente, uma certa compreensão da moral.

Devido à maneira geral com que Nietzsche julga a antinatureza da moral, esta é considerada como erro que pervade logo no pensamento anárquico da pósmodernidade, uma norma elementar de toda doutrina sapiencial. Isto é visto como uma espécie de perversão da ordem natural das coisas porque dessa norma, dessa negação, nada resulta, senão uma gélida conformidade servil a uma lei autoritária que traz consigo uma dissolução do próprio sujeito, uma inclinação niilista e passiva diante da moral que dita normas como vontade de vida, impedindo que a vida surja de dentro do ser humano como vontade de vida. A vontade de vida que se expressa em relações sociais de reciprocidade.

\section{A política recíproca reconciliada}

O ethos cristão que, além de fenomênico, possui uma fundamentação lógica e uma implicação política, marcada pela transição da esfera do privado e estranho para a esfera do público e reconciliado - o legado cristão na história. É uma história que se expressa na abertura da reconciliação e em valores sempre novos que se vão implantando pela sua transvaloração, em redes potenciais e múltiplas, portanto na Gegenseitigkeit (reciprocidade). Essa reciprocidade se manifesta tanto na reconciliação de partes, no "(...) Ser [é] a síntese do sujeito e do objeto, no qual sujeito e objeto têm perdido sua oposição" (HEGEL, ECD, TWS, 1994, p. 326), como na totalidade caótica das mesmas em "(...) Deus como momento culminante: o ser aí, uma eterna adoração e acentuação. Porém, nisto, não é a palavra ponto culminante senão apenas pontos culminantes de potência" (NIETZSCHE, FP Outono 1887-9 [8], KSA, 1999, p. 343); permanece um todo em rede, cujas relações se dão através de ações que respondem a estímulos na mesma intensidade, sejam estes estímulos que reconciliam e que provocam a luta. Na reciprocidade, a prática original de Jesus, que é força, se opõe àquilo que ameaça a sua diversidade; afirma o aspecto da coletividade que se efetiva na política ao se reconciliar as diferenças, no intuito não de negar seu princípio de diferença e individuação, mas de reforçar sua identidade como diferença. Na reconciliação não há eliminação das diferenças, mas a reconciliação, com recorda Agemir Bavaresco, é em si motor da manutenção das diferenças. "Trata-se da busca da identidade na diferença dos opostos do entendimento, reunindo-os em um momento de totalidade em que ambos os termos contraditórios não são absolutamente negados, mas conservados e reunidos com suas

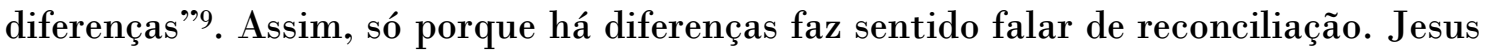
testemunha a afirmação das identidades nas diferenças ao estabelecer relações com

${ }^{9}$ Cf. BAVARESCO, 2011, p. 33

FEILER, Adilson Felicio. A ética cristã a partir de uma leitura de Hegel e Nietzsche. Griot : Revista de Filosofia, 
povos estrangeiros. Nestas relações se aprimora a dimensão da universalidade no sentido de se acolher o destino com amor.

A vida, compreendida como plenitude Lebensfülle, é própria de uma compreensão romântica. No entanto, o Romantismo filosófico abarca, dentro de seus limites, posições que, desde o ponto de vista doutrinal, são completamente heterogênas: tal como é o caso de Schelling e Marx, ou de Fichte e Schopenhauer. Contudo, Hegel e Nietzsche também são heredeiros genuínos do Romantismo, ainda que habitem em universos separados.

Há certa compreensão judaica de Deus sobre a qual não é possível uma unificação real com Ele e, deste modo, ao apresentar-se Deus como um poder que exige obediência ao ser humano interpela desde fora. Por isso, tal compreensão faz do Judaísmo uma religião essencialmente positiva. Por essa mesma razão, no conceito fundamental de Deus, assim como uma certa compreensão judaica do tema apresentado, não é possível uma unificação real. Deste modo, o apresentar de Deus como um poder que exige obediência e que interpela ao homem sempre "desde fora" torna a religião judaica essencialmente positiva. Porém, se Jesus supera esta positividade, não é porque substitui a heteronomia, a lei da religião, pela autonomia da lei moral; Hegel fala de um "espírito de Jesus superior à moralidade" e vê, em consonância com ele, seu próprio despojar das leis, sua determinação propriamente legal e formal. Jesus significa o $\pi \lambda \eta ́ \rho \omega \mu \alpha$ (pleroma), o cumprimento e, ao mesmo tempo, a superação radical da lei moral em sua forma kantiana, na medida em que esta também supõe uma separação que pode ser superada: a contraposição entre o dever e a inclinação, entre o homo noumenon e o homo phaenomenon. A prédica de Jesus apresenta o imperativo categórico; seu conteúdo é a presença do espírito, o amor e a vida, porque só mediante o amor cai o poder do objetivo.

Diante da alternativa de compartilhar o destino, isto é, a existência positiva de seu povo, ou perecer, Jesus se decide pelo último. Depois de sua morte se reúnem seus discípulos em nome do amor ensinado e vivido por Jesus, porém ao fazê-lo vinculam o "espírito" do Cristianismo com uma existência positiva e fazem surgir um espírito positivo de uma religião que oscila, na história, entre aquela união originária de onde procede e uma série de divisões inevitáveis, que mediam, por exemplo, a divisão entre o Estado e a Igreja, que esse espírito não pode superar. A comprensão do fenômeno do Cristianismo como práxis ética é o que permitirá estar mais próximo à mensagem pregada e vivida por Jesus. Neste sentido, sem invalidar todo os esforços seculares de inúmeros teólogos, a interpretação que Hegel e Nietzsche realizam sobre o Cristianismo consiste em uma tentativa de mostrar que esse modelo autêntico de Cristianismo se alia a uma religião do coração, como plenitude da existência. Essa maneira de compreender o Cristianismo é reconciliação entre os polos da dialética e transvaloração de todos os valores, que funciona como dinamite de toda a velha estrutura sobre a qual estava edificada a cristandade.

Assim, o Cristianismo, compreendido sobre a ótica da plenitude vital, confere um caráter eminentemente plural, francamente posmoderno, doador do princípio do pluralismo radical, o que está de acordo com os ensinamentos de Jesus, segundo o qual, cada um deve seguir-Lo porém de cordo com o seu modo próprio.

A ideia da plenitude vital como uma espécie de "ideal dionisíaco", que não conhece barreiras, se vê projetado sobre o ethos cristão em termos tais que este 
parece cair desfigurado. Assim, ocorre, por exemplo, com o modo pelo qual as "inclinações" cumprem o seu papel, como o contrário da rigidez da lei e da moral, sem as devidas distinções, como se fossem um valor positivo por si, ainda embora o próprio Cristo dizesse que o que contamina o ser humano não é o que entra nele, mas o que sai dele (Mc. 7, 21-23; Mt. 15, 19-20). A mensagem original do Cristianismo de Jesus leva a não nos fixarmos em tudo aquilo que impede o movimento e a abertura. Esta é a singularidade de sua mensagem; um projeto ético baseado na própria pessoa de seu fundador que valoriza o todo da vida humana, inclusive sua inclinações. Assim, ao invés da rigidez legalista da moral, Jesus apresenta a eticidade como uma dimensão mais livre e mais humana da existência, mais rica enquanto fenômeno de comunicação e de participação.

Nosso esforço de vincular Hegel e Nietzsche a uma leitura sobre o ethos cristão não ignora os vários teólogos que muito ajudaram a esclarecer o fenômeno do fato cristão, contudo nossa proposta é a de nos centrar unicamente em alguns pontos comuns em Hegel e Nietzsche, acerca deste assunto.

\section{Conclusão}

Assumir o destino é maximizar a vida e intensificar a potência, de modo que esta alcançe seus pontos culminantes que se efetivou na prática de vida de Jesus, para além do Judaísmo e do Cristianismo de seus seguidores. A verdadeira religião é aquela que maximiza a prática de vida: Lebenshöhepunkte, razão pela qual afirmamos que esta se deu na atuação de Jesus, que inaugurou uma ética desde o seu aparecimento ao afirmar a vida e suas inclinações pela Leistungsfähigkeit (potencialidade), em seu desdobramento e oposição pela Vielfältigkeit (diversidade), ao negar o que se opõe à vida, e em sua reconciliação e redes constituídas por pólos em luta pela Gegenseitigkeit (reciprocidade) acolhendo as identidades nas diferenças. É claro que esta religião poderia continuar acontecendo através da constituição de pequenas comunidades imbuídas do princípio de afirmar a vida pela prática no reconhecimento das diferenças promotoras de uma sempre nova Leistungsfähigkeit (potencialidade). É justamente pelo reconhecimento das diferenças como diferenças, portanto com características múltiplas, que se é capaz de apresentar em Nietzsche um projeto ético; uma ética da intensificação da potência que é expressão de uma dada condição de vida: amor fati. Diante dessa ética é-se levado a enfrentar o fluxo vital dentro daquilo que este apresenta de mais terrível. Pois, o que se tem até agora convencionado é que, por trás do quadro caótico que este apresenta do mundo, nada se contrói; não se contrói nada quando se atrela aos moldes da moralidade clássica e à sua versão moderna, que cristaliza as diferenças. Ora, são, portanto, essas diferenças as promotoras de vida, expressas na reconciliação de redes que se opõem e atingem pontos culminantes: Lebenshöhepunkte que acolhem e afirmam com amor o destino. Porém, estes são apenas pontos, resultantes da intensificação da potência como necessidade orgânica do próprio agir, de docilidade ao destino, dos quais se constituem novas forças que, ao se diferenciarem criticamente, se atualizam reciprocamente para dar espaço a novos pontos culminantes, e assim sucessivamente. Portanto, maximiza a vida todo aquele que supera os limites do estranhamento da

FEILER, Adilson Felicio. A ética cristã a partir de uma leitura de Hegel e Nietzsche. Griot : Revista de Filosofia, 
lei positiva e a resignação moral do último homem no ethos que é base para a praxis, o que reflete de modo particular a prática de Jesus.

Essa atualidade, que de uma fenomenologia como Leistungsfähigkeit, passa por uma lógica da oposição e da diferença como Vielfäligkeit, se reconhece como diferença na Gegenseitigkeit (reciprocidade). Tanto na reconciliação das partes, como na totalidade caótica das mesmas permanece um todo em rede que reconhece as diferenças. A prática de Jesus se apresenta como aquela potencialidade que é o Reino de Deus se opondo àquilo que não lhe corresponde: a fixidez da moral, afirmando a diversidade em que se reconhece e afirma a diferença. Estes momentos ou estas etapas categoriais, são permeadas por avanços e retrocessos, por vitórias e fracassos, pela totalidade e pelo sectarismo, cuja tensão resulta em culminâncias potenciais. Na inclusividade da prática de Jesus o todo é reconciliado transvalorativamente; o destino é acolhido com amor. Não é um amor vazio e abstrato por Jesus retirar-se do mundo ao anunciar o Reino de Deus, pois age segundo uma prática que rompe a blindagem da unilateralidade positivista. Esta disposição inclusiva de Jesus o redime, inclusive, da crítica hegeliana de sectarismo, pois acolhe o todo em instantes de plenitude transvaloradas, como amor fati. Ao retirar-se do mundo, ele eleva a vida à sua culminância. Cada instante vivido no processo do retorno é pleno e atinge a sua culminância de vida, portanto uma reconciliação instantânea, sempre em movimento.

Logo, o Cristianismo do movimento messiânico de Jesus promove um ethos cristão que intensifica a vida até a sua plenitude e culminância: Lebenshöhepunkte pelo amor com que se acolhe o destino. 


\section{Referências bibliográficas}

BAVARESCO, Agemir. Estatuto lógico da alteridade hegeliana. Síntese, Belo Horizonte, v. 38, n. 120, p. 27-53, 2011.

BECKENKAMP, Joãozinho. O jovem Hegel. Formação de um sistema pós-kantinano. São Paulo: Edições Loyola, 2009.

BRITO, Emílio. La vie dans 'L'esprit du Christianisme'. In: Hegel e la vie. Paris: Librairie Philosophique J. Vrin, 2004, p. 17-18.

DILTHEY, Wilhelm. In: Hegel-Studien. Band 1. Bonn: Heraugegeben von Friedheim Nicolin and Otto Pöggeler, 1961.

GIACÓIA JÚNIOR, Oswaldo. Nietzsche como psicólogo. São Leopoldo: Editora Unisinos, 2001.

HEGEL, G. W. F. Frühe Schriften. Werk 1 Suhrkamp Taschenbuch Wissenschaft. Frankfurt: Frankfurt am Main, 1994.

, O Espírito do Cristianismo e seu destino. In: Revista de Opinião Filosófica, n. 02, v.01, Porto Alegre: EdiPUCRS, Jul/Dez. de 2010 (por nós traduzida).

HOULGATE, Stephen. Hegel, Nietzsche and the cristicism of metaphysics. Cambridge: Cambridge University Press, 1986.

KAUFMANN, Walter. Nietzsche, philosopher, psychologist, Antichrist. Princeton: Princeton University Press, 1968.

KRELL, David Farrel. Postponements. Woman, Sensuality, and Death in Nietzsche. Blowington: Indiana University Press, 1986.

KÜNG, Hans. Incarnation de Dieu. Introduction à la pensée théologique de Hegel commo prolégomènes à une christologie future. Bar-le-Duc (Meuse): Desclée de Brouwer, 1973.

LÖWITH, Karl. Von Hegel zu Nietzsche. Der revolutionäre Brunch im Denken des neuzenten Jahrhunderts. Stuttgart: J. B. Metzlersche Verlagsbunchhandlung, 1988.

NIETZSCHE, F. W. Sämtliche Werke Kritische Studienausgabe in 15 Bänden. Herausgegeben von Giorgio Colli und Mazzino Montinari. München: Deutscher Taschenbuch Verlag de Gruyter, 1999.

O Anticristo, maldição do cristianismo e Ditirambos de Dionísio. São Paulo: Companhia das Letras, 2007.

, Assim falou Zaratustra. Civilização Brasileira: Rio de Janeiro, 1998.

PIPPIN. Robert B. Nietzsche, Psychology, and First Philosophy. Chicago: The University of Chicago Press, 2006.

RICOEUR, Paul. Ética. Da moral à ética e às éticas. In: Dicionário de ética e filosofia moral. Vol I, São Leopoldo: Editora Unisinos, 2003, p. 591.

TORRES, João Carlos Brum. Hegel e o destino. In: Hegel: a moralidade e a religião. Filosofia Política, série III - n. 3, Rio de Janeiro: Jorge Zahar Editor, 2002.

VATTIMO, Gianni. Depois da cristandade. Por um Cristianismo não religioso. Rio de Janeiro / São Paulo: Editora Record, 2004.

Autor(a) para correspondência: Adilson Felicio Feiler, Universidade do Vale do Rio dos Sinos, Av. Unisinos, 950, Cristo Rei, CEP 93020-190, São Leopoldo - RS, Brasil. afeiler@unisinos.br 